This is an author-produced PDF of an article published in the International Journal of Music Education. Copyright SAGE. Until publication, citation information is:

Bartleet, B.-L., C. Grant, C. Mani \& V. Tomlinson (in press). Global mobility in music higher education: Reflections on how intercultural music-making can enhance students' musical practices and identities. International Journal of Music Education. doi: $10.1177 / 0255761419890943$

\title{
Global mobility in music higher education: \\ Reflections on how intercultural music-making can enhance students' musical practices and identities
}

\author{
Brydie-Leigh Bartleet, Catherine Grant, Charulatha Mani and Vanessa Tomlinson
}

\begin{abstract}
Music higher education institutions are increasingly recognising the educational value of intercultural learning experiences. Delivering such learning experiences in a way that provides music students with a rich cultural and musical learning experience, rather than a superficial one, can be a challenging task, particularly in the case of short-term 'mobility' or 'study-abroad' programs. This paper explores ways to address this challenge by reflecting on student learnings from a suite of international study experiences, or 'global mobility programs', at one Australian tertiary music institution, run in collaboration with community partners, universities and NGOs in the Asia Pacific. Focusing on how intercultural musicmaking in the context can enhance students' musical practices and identities, we first outline the sociocultural contexts of our music global mobility programs in Cambodia, China and India, and explore the different modes of music-making these experiences afforded. We then draw on Coessens' "web of artistic practice" to explore site-specific examples of the ways in which global mobility programs can enhance students' musical practices and identities. These findings hold particular relevance for music educators and higher education institutions in justifying, designing and carrying out such intercultural experiences to maximise student learning and success.
\end{abstract}

\section{Keywords}

Global mobility; higher education; intercultural learning; music-making; student identities

The musical practices that music students engage with during their education, and the musical (and nonmusical) identities they develop during this time, have substantial bearing on their later lives and livelihoods as musicians and citizens (Elliott, Silverman \& Bowman, 2016). A growing body of literature underscores the potential lifelong personal, professional, and societal benefits of a socially and culturally engaged tertiary music education (Baxter, 2007; Elliot, 2012, Vaugeois, 2009). In this regard, some scholars point to the particular value of intercultural music learning, which among other things can assist 
students to rethink and expand their beliefs about what it means to be a musician and to make music (Bartleet \& Carfoot, 2016; Grant, 2018; Harrop-Allin, 2016). Further, it seems important that music educators understand the interrelationships between the intercultural learning experiences they offer and their students' beliefs, values, and practices relating to music, since these interrelationships have curricular and pedagogical implications, as well as broader implications for students' lives and careers (Westerlund, 2019). To this end, this article examines these issues in the context of one particular kind of intercultural learning experience in tertiary music institutions: the global mobility program.

\section{Global mobility programs in music}

Mobility programs - those where students travel domestically or internationally for an immersive learning experience - offer students an opportunity for learning through lived experience, in contrast to "imagined" engagement with "others" (Bartleet \& Carfoot, 2013). Established benefits of such programs in music and the arts include relationship building and intercultural reconciliation (Bartleet, Sunderland \& Carfoot, 2016); encouraging reflection on self and society (King, 2004); fostering intercultural humility in students, for example through self-reflection (Bartleet, Bennett, Power \& Sunderland, 2016); promoting artistic citizenship (Bartleet \& Carfoot, 2016); helping to meet community needs (HarropAllin, 2016); and developing a sense of global citizenship in students (Grant, 2018). Research on mobility programs in music indicate that music can be "a particularly democratic medium" for learning, and that music-making has the ability to "transcend other communication methods and involve a wordless knowing of others that [become] a basis for relations and interactions" (Adkins et al., 2012, p. 203). This is perhaps particularly true of intercultural mobility programs - that is, mobility programs where the learning is situated in contexts of cultural difference, involving understanding and interacting with people from cultural backgrounds other than one's own (Jones, Miles \& Gopalkrishnan, 2018).

This paper explores the question: how can music-making in the context of intercultural mobility programs affect students' musical practices and identities? With reference to three recent intercultural mobility programs delivered by one Australian tertiary music institution, we first provide a brief background to each of these programs and their institutional setting. We then explain what we mean by 'music-making' in the context of these three programs, before turning to the effect of that music-making on the musical practices and identities of the participating students. To do this, we draw on Kathleen Coessens' "Five dimensions" (2014) of artistic research to examine the ways in which knowledge can be transferred to and from an artistic web of practice in these programs. Through these five dimensions - embodied artistic know-how, personal knowledge, the environmental, the cultural-semiotic, and the receptive - we provide site-specific examples of the ways in which global mobility programs can enhance students' musical practices and identities. In this way, we reflect on the uniqueness of the act of music-making in intercultural mobility programs, particularly in relation to students' musical practices and identities. In doing so, we aim to contribute to a better understanding of the nature, importance and value of intercultural learning through music, particularly in the context of intercultural mobility programs.

\section{Setting the context}

The project that informs this paper aimed to enhance intercultural mobility programs for students in music at Queensland Conservatorium Griffith University, Australia, providing a coordinated suite of 
infield initiatives with partners in the Asia Pacific. The project is situated in a wider context where Australian (and other) higher education institutions are increasingly recognising the need to systemically embed international study experiences into their curriculum (Deardorff, 2004; Lewin, 2010; Jones, 2010), and are acknowledging the important role these experiences play in preparing work-ready graduates who have appropriate competencies and proficiencies to take their role as global citizens (Bridgstock, 2009). The project delivered three mobility programs with long-standing partners in China, India, Cambodia. All three programs were founded on strong relationships between the program facilitators and these partners, built over several years. Key pedagogical aims were for students to develop their intercultural awareness through music and music-making, a sense of social responsibility and global citizenship, and the skills to critically reflect on their own cultural subjectivities as musicians. In all cases, the trips intentionally avoided the observational 'cultural tourism' approach to mobility programs, instead being based on principles of participatory, embodied, and immersive learning in partnership with the host communities.

The facilitators selected the participating students (see below), prepared the students pre-trip, organised the program of activities, liaised with local partners, led the course learning, provided pastoral care to the students, and marked course-related assessment. The facilitators of the Cambodia and China trips (Dr Catherine Grant and Dr Vanessa Tomlinson respectively) were both full-time lecturing staff members at the university at the time of the program. The co-facilitator of the India program, Dr Charulatha Mani, a Carnatic singer/pedagogue, was the vocal guru in the trip (in the broad sense of being 'teacher' or 'guide' in a particular field or skill), as well as being research assistant on the project at large; she was supported in the facilitator role by a full member of staff who also accompanied the students on this trip. Firstnamed author Prof Brydie-Leigh Bartleet oversaw the project development and implementation, participated in student assessment design and moderation, conducted a small set of student interviews post-trip, and led the research project relating to the mobility program (see further next section).

Students applied to participate in the project; selection criteria for each group included ensuring a balance of musical skills and instruments, and a gender balance as far as possible, for each group, as well as the degree to which each individual student's stated reasons for applying aligned with the pedagogical intentions of the program. Students were aged 19-29, 7 male and 10 female. One student identified as Singaporean and another as Chinese-Australian; the others identified as Australian. Students were enrolled in the Bachelor of Music, Bachelor of Music in Education Preparation and Bachelor of Music (Honours), and all were between the second and final year of these programs. Their specialisations were Western classical music (14), jazz (3), and music education (2) (non-mutually exclusive), and they played a range of brass, wind, string, and percussion instruments and voice.

The three mobility trips took place simultaneously for 10 days. Selected students attended a series of predeparture information sessions around travel, health and safety, behaviour and participation expectations, and assessment requirements. An internal university learning-and-teaching grant subsidised the facilitators' travel and general program costs, with additional partial funding for students provided by the university mobility office; students could apply for a government loan for remaining costs. Students received credit for their enrolment in the course, and were assessed on their in-field participation, and 
two reflective assessment items (a written creative journal and a digital story, presented to students and other members of the university community upon their return home).

\section{China}

For the China program, six students visited Chengdu and XiGong in the province of Sichuan, with the goal of learning folk music and Sichuan opera traditions in that area. Both these traditions are well known to the facilitator (Tomlinson), through over 15 years of research into these practices. Because of this history, close contacts with leading musicians, cultural supporters (Dufu's Cottage, Australian Embassy, Chengdu, Chengdu Cultural Ministry, Sichuan International Friendship Society), and friends were drawn upon in constructing the learning environment and itinerary for this program. The group comprised a fourth-year percussionist (M, 22), an honours-level composer (M , 22), a third-year classical pianist (F, 27), a second-year clarinetist (F, 20), a second -year jazz bassist (M, 20), and a third-year violist (F, 20). A full-time local translator was incorporated as part of the team, plus local organisers who assisted with logistics such as purchasing concert tickets, setting up lessons and cultural activities, and advising on current conditions in an ever-changing city. Students were exposed to local musical customs through oldstyle teahouse opera performances, tourist operatic performances and the world premiere of a new Sichuan Opera. The student group presented two significant performances in collaboration with local Sichuan students, sharing their musical traditions including a work by one of the touring party, a selection of Western classical music, improvisations, and performances of newly acquired skills in Sichuan folk and opera music. They were simultaneously ambassadors for Western musical traditions (jazz, experimental and classical in particular), and beginning student collaborators in Sichuan music traditions. Students undertook daily lessons in Sichuan Opera voice, suona, percussion, and zither, regardless of their main instrumental focus at the home institution. In addition, students were immersed in cultural activities, from visiting pandas, to learning about Taoism and Buddhism through visiting temples and climbing sacred mountains, exploring a range of local spicy cuisine, being hosted by the Australian Embassy, visiting statues of Mao, Dufu's cottage and Tibetan neighbourhoods and finally being immersed in the navigation of a city of 12 million Sichuan and Mandarin speaking people. Each of these activities provided ample opportunity to discuss Chinese history and to discuss different value systems and approaches to issues politically, culturally and socially.

\section{India}

Six students visited Chennai, India, and engaged with performer/pedagogues from the Carnatic system of music at an institution (Swarnabhoomi Academy) as well in a conventional guru-sishya learning method. The student group comprised a third year Jazz singer (F, 22), two third year composers (M, 27 and De-identified, 21), one percussionist (M, 21), a third-year French Horn player (F, 22) and an honours level violinist (F, 24). In the guru-sishya learning phase of the program, the students observed traditional Carnatic practices and actively participated in the music-making by receiving from and responding to 'vidvans' (masters in their field), including those from the Nagaswaram (a wind instrument played mainly at temples and festivals), Thavil and Mridangam (percussion instruments) traditions. They responded with their instruments and/or voices, and although they initially identified themselves with the specific roles that they had entered the program with, such as singer, percussionist, or composer, as the program progressed, they engaged in a broader sphere of music-making. The composers sang, the Jazz 
singer played the Veena, and the percussionist took an interest in Carnatic vocal ornamentation. The India cohort spent a week at Auroville, a culturally diverse community in the outskirts of Chennai. Auroville is a settlement of people from various parts of the world, and sustains a confluence of languages, foods and cultures while retaining the Indian backdrop (Kapoor, 2007). The vocal workshops conducted there were attended not only by the students, but also by musically interested members of the community, including music professionals and amateurs. The students shared information on their instruments, their normative repertoire, and music-related lifestyle in Australia, with the locals. In the workshop, the students were introduced to the concept of ornamentation (gamaka) by aurally and orally engaging with the Carnatic Raga, the basic melodic material of South Indian music. The students visited the Matri Mandir (a spiritual site in Auroville) almost daily for meditation sessions, and the field trip to Aurobindo Ashram in Pondicherry introduced them to the concept of spirituality from an Indian perspective.

\section{Cambodia}

Five students travelled to Cambodia's capital city, Phnom Penh, to collaborate with local artists and nongovernment arts organisations on a range of musical and cultural activities. The student group comprised a second-year saxophonist majoring in education preparation (F, 20), a second-year percussionist (M, 19), a third-year trumpet player (M, 20), a third-year composer (M, 23), and an honours-level jazz guitarist $(\mathrm{F}, 21)$. Most students had musical skills in areas other than their study majors. Facilitated and enabled by the host Non-Government Organisations Music Arts School (MAS) and Cambodia Sings, the students visited several schools in 'slum' communities (the term used by MAS) to facilitate short performance and participatory workshops that included Cambodian traditional, Cambodian popular, and Western tunes. At MAS, students often jammed informally with Cambodian youth, some of whom played Western instruments (piano, guitar), others traditional ones. They participated in a half-day traditional instrument workshop, simultaneously grappling with a new instrument (chapei dong weng), new repertoire (traditional Khmer melodies), and a new way of learning music (completely aurally, and outside of any aural framework that was familiar to them). They delivered an 'instrument sharing' workshop open to the public, in which Cambodian musicians and the students taught each other about their instruments and music. Students also participated in a shadow puppet (sbek touch) class, a local community choir rehearsal, and various other informal social and cultural activities throughout their trip. Many of these opportunities for learning and exchange arose day-by-day from the prior relationships in Cambodia of the trip facilitator [removed for blind review], who had lived in Cambodia for 6 months the

year before the mobility trip, and who had carried out annual research fieldwork in Cambodia since 2013. Further information about the activities of the Cambodia trip, as well as outcomes for students in terms of fostering a sense of global citizenship and social responsibility, are reported in Grant (2018).

\section{Research approach}

An overarching research project called Developing and sustaining music mobility programs in the AsiaPacific, funded by a competitive university grant, underpinned these mobility programs. Qualitative data was collected at key points throughout the project in order to reflect on the learnings that were taking place. With the students' informed content (and ethics approval from the university), their written creative journals and digital stories, which were assessment items for the course, formed data for the 
research. In addition, the facilitators conducted research focus groups and informal interviews with the students during the trips, focusing on what the students were learning, their observations of the cultural experience, and reflexive understandings of their own cultural subjectivities. Research project leader [name removed] also conducted informal interviews with five self-selecting students on their return to Australia, to seek their post-trip views. Sample questions for these focus groups and interviews include: What are your main musical and non-musical learnings from this experience? (How) has the trip make you think or feel differently about music or music-making? What were some challenges for you of making music in this intercultural context? All focus groups and interviews were recorded and later transcribed. Each facilitator also wrote in-field and pre-trip and post-trip written reflections, which formed another layer of observational data.

The research team worked with an external evaluator who provided formative and summative feedback on this raw data, including students' creative journals, digital stories, formal evaluations of the course, and the facilitators' written reflections (further information is published in the project's report, [removed for blind review]). All raw materials - student creative journals, digital stories, focus groups and interviews, and facilitator written reflections - were inductively thematically coded (Guest, MacQueen \& Namey, 2012) in an iterative collaborative process by the four authors of this paper. We then crossmapped this coding to the theoretical framework of Coessens (2014) as described below, finding that this framework allowed us to more clearly structure and articulate our understandings of the ways in which this intercultural mobility program enhanced participating students' musical practices and identities.

\section{Defining music making in global mobility programs}

Defining 'music making' in the context of global mobility programs is particularly complex. This is due to the somewhat unstable, risky, disruptive nature of in-field musical encounters, and due to students becoming aware and acting upon a sense of new musical awareness. In conceptualising these musical encounters, we have found it useful to conceive of 'music making' in the broadest sense: engaging with self and other through music. Although the practicalities of how we went about this varied from context to cultural context, all three of our programs had much in common in the way we approached musicmaking. Table 1 extrapolates specific ways in which these musical encounters were enacted in-field.

Table 1. Representative typology of music-making in the context of our three music mobility programs

\begin{tabular}{|c|l|}
\hline Act of engagement & Examples of music activities during the mobility programs \\
\hline $1 . \quad$ Speaking & $\begin{array}{l}\text { With musicians, music instrument makers } \\
\text { With students, teachers } \\
\text { With each other }\end{array}$ \\
\hline $2 . \quad$ Listening & $\begin{array}{l}\text { To lessons of local students } \\
\text { To professional performances in local settings } \\
\text { To peers - local students } \\
\text { To language } \\
\text { To marketplaces, natural sounds, urban sounds (Soundwalk) } \\
\text { To lectures on musical subjects }\end{array}$ \\
\hline
\end{tabular}




\begin{tabular}{|c|c|}
\hline 3. Learning & $\begin{array}{l}\text { Attending lessons with Masters of particular traditions } \\
\text { Learning to play particular pieces of music } \\
\text { Learning different approaches to music-making, in different learning / } \\
\text { transmission environments }\end{array}$ \\
\hline 4. Teaching & $\begin{array}{l}\text { Student to student teaching } \\
\text { Master to student teaching } \\
\text { Student to Master teaching }\end{array}$ \\
\hline 5. Visiting & $\begin{array}{l}\text { Temples, spiritual and religious sites } \\
\text { Music schools, sites of cultural practices }\end{array}$ \\
\hline 6. Sharing & $\begin{array}{l}\text { Musical and cultural information with each other and with hosts } \\
\text { Instrument-sharing } \\
\text { Musical practices }\end{array}$ \\
\hline 7. Practising & $\begin{array}{l}\text { Existing skills } \\
\text { Newly acquired skills }\end{array}$ \\
\hline 8. Composing & $\begin{array}{l}\text { New music inspired by local context and culture } \\
\text { New music inspired by local musical instruments, techniques, genres }\end{array}$ \\
\hline 9. Improvising & $\begin{array}{l}\text { With local musicians, students, teachers } \\
\text { Jamming together }\end{array}$ \\
\hline 10. Performing & $\begin{array}{l}\text { Performances of pre-prepared material, and of recently acquired skills } \\
\text { Performing in collaboration with local musicians } \\
\text { Playing without an audience, exploring ideas with local musicians }\end{array}$ \\
\hline $\begin{array}{l}11 . \\
\text { Reflecting/Realising }\end{array}$ & $\begin{array}{l}\text { Ruminations in moments of tranquility in a new environment } \\
\text { Realising as they acted, that they possessed multiple performative identities. }\end{array}$ \\
\hline
\end{tabular}

Across each of these eleven acts of engagement, learning the art of flexibility - being able to take in information and respond-became an essential music-making tool for the participating students. The cultural newness of the sites of the three mobility programs demanded a level of openness to uncertainty and fluidity, both from students and facilitators. Such openness is arguably essential to success in intercultural music-making, where students were "socially embedded in dialogue, education, transmission, and exchange" (Coessens, 2014, p. 62) within an ever-expanding web of practice. The words that the students later chose to describe the feelings they experienced while making music in-field: "freedom", "soulfulness", "openness", "trepidation" and the "joy of making sounds with others", amply demonstrate this nexus between growth of practice and identity, and the association of this expansion with a greater joy. We thus define music-making in its broadest sense, not only as an act, but also as a state of being, acquiring and giving.

\section{Five dimensions of music making in global mobility programs}

In order to further explore these various modes of intercultural music-making and their effects on students' musical practices and identities, we now turn to Kathleen Coessens' (2014) "web of artistic 
practice" and its five dimensions of engagement — embodied artistic know-how, personal knowledge, cultural-semiotic codes, ecological environment, and interactivity. We selected Coessen's five dimensions for this analysis as it provides a useful and accessible framework for examining the complex dynamics of music-making that we observed in these intercultural mobility programs, and for exploring site-specific examples of the ways in which these programs can enhance students' musical practices and identities. Figure 1 represents these five dimensions.

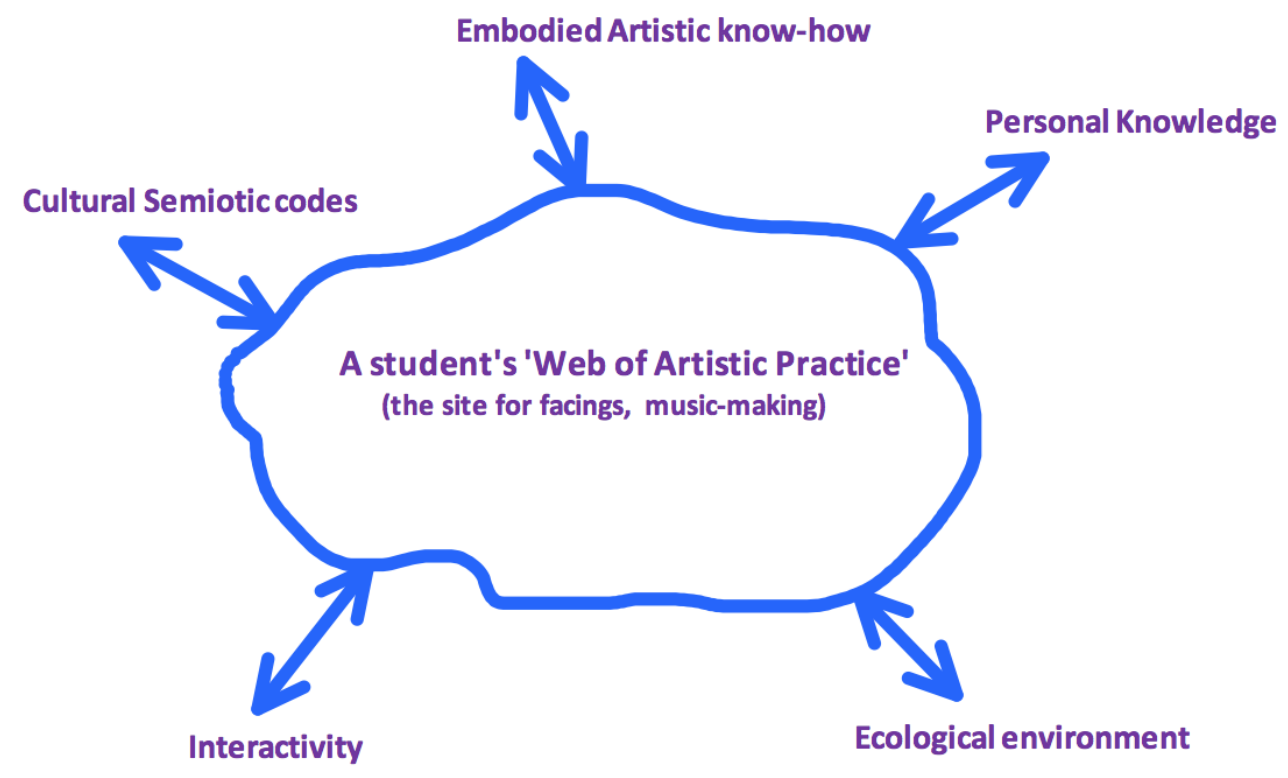

Figure 1. Adapting Coessens' "Five dimensions" of knowledgetransfer to explain experiential learning in and through music-making $(2014$, p. 70$)$

In the following section, we draw on these five dimensions as a framework for sharing site-specific examples of the ways in which intercultural mobility programs can enhance students' musical practices and identities. In so doing, we refer to several of the diverse acts of music-making outlined in Table 1. Underpinning each dimension of this framework is a reorientation and augmentation of musical practices. The thresholds of the practices become challenged with each act of engagement. As Coessens (2014) describes, "[ $\mathrm{t}]$ his web of artistic practice constitutes a robust but flexible scaffold and is continually developing and augmenting artistic expertise" (p. 70).

\section{1) Embodied artistic know-how}

Coessens (2014) believes that artistic creation means "taking action in an embodied way", that "every process of creation contains instances of embodied performance combining different skills, perceptual capacities, and sensory-motor coordination. The body of the artist is his or her first medium of expression" (pp. 70-71). This "dimension" of engagement is well exemplified by the Indian mobility program, where the students listened to the voice of the teacher, observed the embodied gestures that sometimes accompanied, and at other times prompted, the melodic contour of a Carnatic Raga. They attempted to reproduce what they believed they heard and saw, while also drawing on the skills that they 
possessed. At this stage, they were given feedback from the guru, and attempted the imitation again. This iterative loop was allowed to play out supplemented by a visual learning aid, the pedagogical tool 'RagaCurve' developed by the co-facilitator of this program (Mani, 2018). Whether students would have 'learnt' the Indian Raga, Tilang, thus taught, is a question that prompts a cursory glance at the notion of learning in the Indian context. The traditional guru-sishya learning constitutes a deeper, long-standing engagement with a guru in music-making that would eventually lead to the student acquiring knowledge (Krishna, 2013). Learning Indian music is a lifelong experience for many, and relates "not only to learning musical materials but also to the enculturation of approaches to a musical style" (Schippers, 2009 , p. 62). However, in this instances, the students were introduced, albeit briefly, to the approach of embodied musical learning: the wave of the tala (time-keeping using the palms), a tilt of the head from the guru, an unconscious sketch of the ornamentation in air, were just a few instances of such engagement. Key phrases from the student data reflect the extension of this idea further into the domain of cognition: 'aural-oral skills,' 'teacher-student body language,' 'memorising as a method,' and 'selfcorrection using sensory-motor skills.' The context of India where music is never 'text' but always 'act' was a productive site for students to recognise music through their embodied involvement. As one student later affirmed:

You have to internalise it in your body. It means nothing on the page. So, to discover it, I almost feel like you learn it through your motor-neural side of your brain first, and then understanding can come later. (personal interview, 2016)

In Cambodia, students experienced embodied musical practice in ways largely unfamiliar to them from their prior Western musical training. Experiencing music as a fully participatory, immersive activity (in the sense of Turino, 2008) initially came as a surprise, particularly in contexts where the students had conceived of a given activity as presentational, with concomitant expectations of a certain attentiveness from listeners, and a certain authority brought by their own status as 'performers'. On a school visit, for example, when the students played on their Western instruments a couple of well-known Cambodian traditional and popular songs they had prepared for the occasion, the children immediately sang along at the tops of their voices, the instruments hardly heard over the top of them, prompting bemused smiles from the students. Likewise, the first time students performed in a community setting, when they played Western repertoire previously familiar to them as well as newly-learnt Cambodian songs, they were clearly somewhat taken aback when their 'audience' got up and started dancing and singing along. By the last days of the trip, students had become more accustomed to witnessing such embodied responses to music-making, and some had even begun to join in the dancing and singing on occasion.

In the Chinese context, when playing music in this new cultural setting, embodied and culturally specific questions around etiquette arose. Students were asked to present a performance of music that represented their musical training, and in their first concert (on day 3 of their trip) they presented 3 separate classical solos, and a new composition for all 7 of the students. The classical compositions were by far the most challenging - they found themselves wanting to be extreme outward virtuosi, but were distracted by the talking in the audience throughout their performances. They felt under-dressed, under-polished, undervirtuosic. This was especially evident in contrast to the extremely polished and outwardly refined performances of solo classical Chinese music in the same concert. Here the Chinese students seemed to be totally in control, with dress/gesture/performance all aligned. And while the audience still talked 
through their performances, the Chinese students were not at all distracted. By contrast when the entire group performed an original new composition by one of the students Jasmin Leung, it was received with great enthusiasm and no talking. The idea of something new, something beyond what they had imagined, something that inspired a new way of listening and understanding was being greeted with huge and generous enthusiasm was surprising for the touring students. At this time, Western Classical music in Sichuan province is connected to status, and must be presented at the highest level. Western experimental music was seen as new, interesting, intriguing and sparked the most conversation between students and staff at the informal debriefing session the following day. It must be noted that the body language of students changed after this first performance of a brand-new composition. They were excited, proud, supportive about the work, and thought that sharing something unique, Australian and particular was a really special thing. They had been forced to articulate their original ideas about music, non-verbally, and then had received positive audience responses, and general adulation through excessive photographs, and autographs.

\section{2) Personal knowledge}

Many arts educators are well attuned to the fact that a student's personal knowledge is a function of their previous experiences, sociocultural background, education, embeddedness in a culture and a community of artists, as well as the influence of their own characters and temperament. Coessens' (2014) observed: "The artist's actions and outcomes are influenced and constrained by prevailing ideas about art, cultural currents, and aesthetic context. Some of the parameters are well known, others are present, but in an unconscious way" (p. 74). Across all of the mobility programs, students' prior personal knowledge not only affected their approach to intercultural music-making; music-making became the vehicle for expanding that knowledge. In the Cambodia context, for example, the unfamiliar, participatory, immersive, embodied nature of much local music-making (as described in the previous section) disrupted students' established understandings of the social roles and functions of music. In this sense, it also somewhat destabilised students' own established approaches to preparing for musical performance in the context of their conservatorium training (such as highly valuing and ensuring technical excellence and perfection). Over the duration of the in-field program, this disruption of existing understandings about music allowed new learnings to surface, facilitated by reflection - individually (for example through personal journal-writing, a task with demonstrated learning value for students undertaking international study experiences; Russell \& Vallade, 2010), as a group (for example through informal discussions about the day over the evening meals), and through more structured reflective activities (such as through the assessment for the program, which necessitated critical self-reflection). Overall, the students' reflections on music in Cambodia as a joyful agent in fostering sociocultural identity, cultural strength, and connection with community suggested a growing recognition in students that the process of musicmaking, together, could be an end in itself.

On the China program, one student describes how learning in this intercultural context affected her musical practices upon her return to Australia, and is shaping the way she thinks about music and her music-making:

The experience that I had in China in regards to music was very centred around ensuring that character and musicality were the first priority, with technique considered to be a way of 
expressing this, rather than something that must be mastered before adding expression. When I got back I tried to incorporate this reversed approach to music in my practice and performance and, over the past nine months, I have found that this has not only improved my playing, but that I also enjoy playing more and I am able to learn new repertoire at a quicker pace. That was the most valuable learning that occurred throughout the trip for me and has really changed my view on music. (reflective journal, 2016)

In India, the music-making and learning activities introduced the students to instruments that they were unfamiliar with. Applying these instruments to their extant practice opened new channels through which their personal knowledge could interact with the new instrument, as well as with that of each other. The jazz singer on the India program describes one such encounter: "The electronic version of the drone, tanpura, helped engrain the key centre without compromising the focus of the teacher or student. I plan on purchasing one to take home for my own practice" (reflective journal, 2016). For another student of composition, the program experiences aligned with their active advocacy for a new identity, musically, and in gender. The musical identity of this student had shape-shifted from composer to singer to queer community music advocate in the months following the program. Their recall of the impact the program had made on them is evident in this reflection on the trip, several months after: "The trip got me thinking about collaborative approaches to music, and emphasised the importance of community music. I am now looking at the function of the pride choir as a vehicle for queer expression" (De-identified, email communication, 2017).

In many respects these global mobility programs offered students an alternative way of accessing, drawing on, and furthering their personal knowledge. They implicitly and explicitly suggested alternative notions of 'success' in music-making, beyond those characteristic of the academic environment, and for some students these alternative notions widened the possibilities for their aspirations as artists. For this reason (among others), the in-field experience was an ideal site for student introspection on their musical journeys so far and their futures as musicians. Over time, students began to embrace the diverse learning methods they encountered, as well as new techniques of listening, understanding and embodying music.

\section{3) Cultural-semiotic codes}

As Coessens explains (2014), "[s]emiotic and symbolic systems provide the medium-tools, languages, codes - that permit the artist to translate his or her creative thinking and acting into something durable. The discovery, translation, transmission, interpretation, and recording of art depend upon these tools" ( $p$. 75). As the students came to understand, these are deeply culturally specific as cultures develop semiotic systems and develop themselves because of the creation and evolution of these systems. These are "deeply rooted in socio-cultural styles, values, and meanings, as well as linked to technological evolution and cultural means," as such these codes can sometimes "constrain present or further possibilities of conception, interpretation, or adaptation" (Coessens, 2014, p. 75). An example of Coessens' culturalsemiotic codes in the Chinese context occurred during the final concert, with three notable performances, on the last day, after 10 days of immersion. This time the students had had time to develop new ideas alongside their Chinese teachers and fellow Chinese students. The experimental work mentioned above was performed again, this time with the addition of five local student musicians - creating a site for real- 
time collaboration and deep artistic understanding and a shared exploration of these cultural and semiotic codes. In addition, the presence of Australian students performing Chinese folk-songs in collaboration with Chinese musicians, and improvising around the tunes made it possible for the Chinese students to hear and see their own music in a new light. Lastly, the attempt of the Australian musicians to present a medley of Chinese Opera percussion rhythms, conducted by a Sichuan Master Drummer, created in in real-time (as is the tradition), earned the Australian musicians a huge amount of respect from the Chinese student body. Each performance, each piece, provided a totally different site for learning, and exposed a different set of vulnerabilities. Issues around control and flexibility were laid bare, well beyond those that we may consider in the West, especially cultural and semiotic representations of interpretation and improvisation. The boundaries negotiated in performance were new boundaries - safety and exploration, expert and novice, leader and follower, supporter and supported.

For one student on the India program, sharing their music conducting experience with a choir of local Auroville singers at the workshop setting was motivational. The radical difference in the learning and music-making approaches of their choir in Brisbane and the local community of singers at India stemmed from the variance in cultural-semiotic channels of communication. In one journal entry, a student recognises the rarity of musical notation in the performance culture in India, as a learning opportunity: "I felt surprised for a moment that the musicians at the workshop couldn't read music but then I kicked myself - there are so many other ways to learn music without looking at a specific Western code of dots and lines!" (De-identified, reflective journal, 2016).

Another powerful example of Coessens' cultural-semiotic codes was evident in the Cambodia program, as students began to witness and understand the deep cultural embeddedness of music and its relationship to cultural values and meanings. One circumstance that prompted this shift in students was their seeing, for the first time, their own instruments and musical repertoire from the perspective of people from another culture. With the saxophone attracting particular attention, for example, one student found it both rewarding and challenging to find ways to 'explain' the instrument in verbal and musical terms that would be comprehensible to children and adults whose first language was not English, who may have little knowledge of Western musical systems, and who, in nearly all cases, were unfamiliar with the instrument (reflective journal, 2016). Conversely, in terms of developing their understanding of the local cultural embeddedness of music, over time students began to be more aware of the significance of music's relationship to cultural meanings and values. For example, following an educational meeting with representatives from UNESCO and the government's environment department, where students learnt about some initiatives where the performing arts were being used to promote local awareness of Cambodia's environmental concerns, one student reflected that the meeting made her think about 'what I use music for:'

For me, music is usually about self expression, but it can be so much bigger than that. The arts are able to engage people in a way that text books or other traditional educational tools cannot ... the arts allows for greater participation and opportunities to learn by creating. (reflective journal, 2016)

\section{4) Ecological environment}


During these intercultural mobility programs, interacting with the environment was of considerable importance and a key part of the students' musical learning. Coessens (2014) describes this dimension of the web of practice in this way: "All artistic practice is situated: it occurs in an ecological and material setting that creates specific conditions that have an impact on artists and their activity" (p. 75). Across all three trips, many students found it a significant challenge moving from the comfortable familiarity of Brisbane to the intensity of the cities visited - Chennai, Chengdu and Phnom Penh. In each program, the urban environment affected the personal experiences of the students, in ways that sometimes also impacted their musical ones. In Cambodia, for example, several students displayed or spoke about a degree of self-consciousness at their obvious foreigner status: "It's an awkward thing to get used to and I'm not always sure how to respond to it" (reflective journal, 2016). Several students also reported a sense of discomfit at their own position as privileged foreigners, and at locals perceiving them in that way. When it came to working together artistically with local musicians, such self-consciousness was a likely factor in a certain initial discomfit in students, which began to break down only as the Australian students and Cambodian musicians began to interact on a human-to-human level: to make small-talk, crack jokes, have fun, make music, and to work together toward a shared artistic goal.

The spiritual associations that composers from the West have had with India, over the last several decades, are numerous. In the context of this intercultural mobility program, the idea of allowing musical instances to play out and find their own course was an exciting way for the students to build on the "meditative processes" that they engaged with and "transform their abstractness into music" (reflective journal, 2016). The sheer chaos in the roads of India was for students a refreshing phenomenon, a sense perhaps echoed in musical terms by Cage when he described music as 'a purposeless play. An affirmation of life -not an attempt to bring order out of chaos nor to suggest improvements in creation, but simply a way of waking up to the very life we're living' (Cage, 1973, p. 12). The students' voices resonate this idea: "we were driving the first day through chaotic Chennai. It was a symphony of car horns!" (personal interview, 2016).

Other environmental challenges included the unfamiliarity of food and eating conventions, traffic conventions, and language scripts and sounds. In the student body that travelled to China, two of the students were of Chinese descent - one from Singapore, and the other Chinese-Australian. Even these students, who spoke different amounts of Cantonese and Mandarin, were unprepared for the intensity of the immersive Chengdu ecological environment. For many students, the initial reaction to the unknown was to tense up, criticise, observe difference in the form of negatives and to stay close together. As Robert Hughes described it years ago in visual art The Shock of the New for the first couple of days were confronting, destabilising, and difficult. Even for those that had the attitude of embracing the new, they returned home each night exhausted, after having dealt with new ideas, concepts, and images in an ecological environment so different from home.

\section{5) Interactivity}

In terms of the in-field curriculum for the mobility program, interactive musical learning featured strongly. Partly due to the interactive nature of the programs, prioritising community partnerships, the learning context was in a constant state of flux. As Coessens (2014) writes, "the artist's act always 
encounters the other in the creative process, whether another artist or community of artists, listeners or audiences, the public, society, critics, friends and relatives, or, last but not least, him- or herself." As she goes on to describe, different people and the educational environment both have a major impact on artists' practices and identities. Specifically, "during the process of creation, behind the artistic activity, the other is present, whether in person, in judgement or in the self-reflection of the artist" (p. 75).

Interactions that the students had in the Indian context varied between the active verbalised to the tacit embodied, across social and music-making contexts. Both these modes of interaction mapped directly to their web of practice, which was being renewed with every passing experience. The implicit interactions that the students warmed-up to in India were "eye-contact" while making-music, "smiles exchanged" even when mistakes were made, and the "spontaneity" that the creative processes induced in them. As one student observed: "The program helped me consider the importance of opportunities for joy in interaction and human connection when you step outside your bubble and learn something new" (reflective journal, 2016). This comment indicates that this student not only perceived a linkage between interactivity and learning, but could also relate this connect to a sense of well-being, 'joy.'

In Cambodia, observing how music "can be a very natural extension of communication," (reflective journal 2016), several students were struck by the nature of musical interactions, and the social, often spontaneous, natural community-oriented nature of music-making. Student perceptions included the sense that music-making comprised "no pressures, constraints, expectations. Only joy" (reflective journal, 2016). One student contrasted the spontaneity and community-based nature of much musicmaking she experienced in Cambodia with the "stiff" music-making in the institutional context back home (reflective journal, 2016). Another student noted how these musical and cultural interactions then influenced his own:

I came back from the trip with quite a different view on how music relates to culture and community. This kind of learning about music from another culture gave me a reference point to reflect on my own musical practice from, and made me think a lot about what aspects of music are universal and what makes a musical culture unique. (reflective journal, 2016)

In this sense, student learnings on the Cambodia program resonated with the remark of Higgins that " $[\mathrm{t}]$ he recognition, for Westerners, that there are whole cultures who see music as primarily participatory, who see serious music-making as a 'natural' part of life, and who do not think of music-making as a special skill or the province of experts, can reorient their attitude toward music and its place in their lives" (2012, p. 176).

Similarly, one student described the Chinese context as having:

An open-mindedness to experimenting with new music ideas. The exciting world of east meets west music fusion, which is on the rise at the moment as China becomes more prominent in the economy. It has influenced my choices in my final trimester repertoire [...] What better way to travel than to see the world through musical lens! (reflective journal, 2016)

\section{Reflections and implications for global mobility programs in higher music education}


As our framing of music-making against these five dimensions has shown, global mobility programs can become powerful sites for embodied learning and understanding, and affect students' musical identities and practices in deep ways. These programs afford opportunities for individualised learning and can achieve broader educational goals that resonate with recent directions in tertiary music education, including a new emphasis developing students' sense of global citizenship (Bourn, 2010; Grant, 2018), social awareness and responsibility (Arvanitakis \& Hornsby, 2016), and intercultural skills (Brewer \& Cunningham, 2009). As this program demonstrates, global mobility programs can serve to introduce cultural and educational diversity into music curricula; stimulate respect and appreciation for, and engagement with, new musical aesthetics and styles; and challenge the dominant narrative that the Western / European classical tradition is the pinnacle of music - an implicit value conveyed by the structure of many tertiary music curricula in the West (where musics of other cultures and peoples can often be seen as at the periphery). The students' experiences illustrate how, in response to specific intercultural situations and contexts, they are challenged to readjust their prior acquired artistic schema by (re)creating their art and reweaving their webs (Coessens, 2014, p. 80). To do this successfully, the students need to reflect upon dynamic, action-based processes and explore how to internalise these in their bodies and minds (Coessens, 2014, p. 80), in ways that acknowledge and respect the values and processes they encounter in the field. In the words of Buchanan (2017):

Performance study and ensemble participation beyond the Western art music sphere affords an extraordinary opportunity for transformative learning experiences through which the ethical principles of tolerance, mutual respect, and inclusion become embraced, embodied, and performed, and the ragged edges of social difference defused (p.16)

Such intercultural learning experiences, facilitated by music making, can also bring to students a new recognition of what they may be able to bring to their own communities, or other communities. Likewise, they can also bring a recognition that the music-related skills music students may take for granted can be meaningfully shared, whether this be helping writing music down, sharing percussion skills in the street, establishing connection through non-verbal means, and creating a sense of joy. As in this mobility program, intercultural learning experiences can also bring students new recognition of their own cultural subjectivities; a better awareness of the social, political, economic, cultural environment in which they operate as musicians; heightened recognition of privilege and the concomitant responsibilities it brings, including as a musician; and greater recognition of their identities not only as citizens in their local communities or nations, but as global citizens (reported at more length in Grant, 2018).

All these outcomes suggest potentially substantial benefit for students and tertiary music institutions in exploring and expanding opportunities for students to engage in intercultural learning opportunities, such as those afforded by mobility programs. Some studies have raised important concerns and reservations about aspects of such programs, however - including intercultural power imbalances, the charge of elitism, the risk of unsustainability in environmental and program terms, and a lack of sensitivity to adverse or unexpected outcomes (e.g. Bamber, 2008; Bamber \& Hankin, 2011; Grant 2018), and these considerations are indeed important to take into account in planning, implementing, and evaluating such initiatives. Limitations of this particular study include its single-institution, single-program scope; the relatively small number of student participants; and the relatively narrow research focus on students' 
musical practices and identities. The dual role of the authors as program facilitators and researchers, while in many ways a strength, also entails greater subjectivity than a research design where researchers and facilitators play distinct roles. Future research that addresses these limitations could further enrich understandings of the value (and risks and challenges) of intercultural mobility programs.

In many ways, we believe the process of music making in such intercultural contexts can provide students an "unmasking," a revelation of self. Performance and learning in such intercultural settings demand a huge investment of energy from students, as new understandings of artistic practice are negotiated realtime in front of an audience, master teacher, local collaborators, or hosts. The senses are hyper-aware, self-conscious and alert. It is through and by this process of sharing and giving that music plays so rich a role in intercultural learning, even though the pathway might sometimes seem bumpy, frustrating, and disruptive. Once arrived, students often find themselves in a new place, rebuilt and strengthened. In this way, intercultural mobility programs in music seem to be potentially powerful catalysts for deepening and enhancing students' musical practices and identities.

\section{Acknowledgement}

The author(s) received support from the Griffith University Learning and Teaching Grant Scheme (2016) for the research that informs this article.

\section{References}

Adkins, B, Bartleet, B., Brown, A.R., Foster, A., Hirche, K., Procopis, B., Ruthmann, A., \& Sunderland, N. (2012). Music as a tool for social transformation: A dedication to the life and work of Steve Dillon (20 March 1953 - 1 April 2012). International Journal of Community Music 5 (2), 189-205.

Arvanitakis, J. and Hornsby, D. J. (2016). Universities, the citizen scholar and the future of higher education. Hampshire, UK: Palgrave MacMillan.

Bamber, P. (2008). Introduction. In Clarkson, Jean, Bamber, Phil and Bourke, Lorna. (2008). In Safe Hands: Facilitating service learning in schools in the developing world. Trentham Books. Stoke on Trent, UK and Sterling, USA. pp. xiii-xxiii.

Bamber, P. and Hankin, L. (2011). Transformative learning through service-learning: No passport required. Education + Training 53 (2/3): 190 - 206. http://dx.doi.org/10.1108/00400911111115726

Bartleet, B.L. Bennett, D., Power, A., \& Sunderland, N. (Eds.) (2016). Arts-based service learning with First Peoples: Towards respectful and mutually beneficial educational practices. New York: Springer.

Bartleet, B. L. \& Carfoot, G. (2016). Arts-based service learning with First Peoples: Engendering artistic citizenship. In D. Elliott, M. Silverman \& W. Bowman (Eds). Artistic Citizenship Artistry, Social Responsibility, and Ethical Praxis (pp. 339-358). New York: Oxford University Press.

Bartleet, B. L. \& Carfoot, C. (2013). Desert harmony: Stories of collaboration between Indigenous musicians and university students. International Education Journal: Comparative Perspectives. 
Special Issue: Global 21st Century Professionals: Developing capability to work with Indigenous and other Traditionally-Oriented Peoples 12 (1), 180-196.

Bartleet, B. L., Sunderland, N. \& Carfoot, G. (2016). Enhancing intercultural engagement through service learning and music making with Indigenous communities in Australia. Research Studies in Music Education, 38 (2), 173-191.

Baxter, M. (2007). Global music making a difference: Themes of exploration, action and justice. Music Education Research, 9(2), 267-279.

Bourn, D. (2010). Students as global citizens. In Jones, Elspeth (Ed.), Internationalisation and the Student Voice: Higher Education Perspectives, pp.18-29. New York: Routledge.

Brewer, E. and K. Cunningham (Eds.) (2009). Integrating study abroad into the curriculum: Theory and practice across the disciplines (pp. $i$-ix). Stylus Publishing, LLC.

Bridgstock, R. (2009). The graduate attributes we've overlooked: Enhancing graduate employability through career management skills. Higher Education Research \& Development 28 (1), 31-44.

Buchanan, D. A. (2017). Four strategies for 'sound' activism. In The role of ethnomusicology in the $21^{\text {st }}$ century curriculum, Panel at National Association of Schools of Music conference, USA, November 2016. Accessed in print form via SEM Newsletter 51 (3), 3-17.

Cage, J. (1973). Silence: Lectures and writings (2nd ed.). Middletown, CT: Wesleyan University Press. Coessens, K. (2014). The web of artistic practice: A background for experimentation. In Crispin, D. \& Gilmore, B. (Eds.), Artistic Experimentation in Music: An Anthology (pp. 69-81). Leuven: Leuven University Press.

Deardorff, D.K. (2004). Internationalization: In search of intercultural competence. International Education 33(2), 13-15.

Elliott, D. J. (2012). Another perspective: Music education as/for artistic citizenship. Music Educators Journal, 99(1), 21-27.

Elliott, D. J., Silverman, M., \& Bowman, W. (Eds.). (2016). Artistic citizenship: Artistry, social responsibility, and ethical praxis. New York: Oxford University Press.

Grant, C. (2018). Developing global citizenship in tertiary performing arts students through short-term mobility programs. In International Journal for Education and the Arts 19 (15), 1-25. http://www.ijea.org/index.html

Guest, G., MacQueen, K. M., \& Namey, E. E. (2012). Introduction to applied thematic analysis. Applied thematic analysis, 3, 1-21. Retrieved from

Jones, P., Miles, D. \& Gopalkrishnan, N. (2018). Intercultural Learning: Critical preparation for international student travel. Haymarket, Australia: UTS ePRESS.

Harrop-Allin, S. (2016). Higher education student learning beyond the classroom: Findings from a community music service learning project in rural South Africa. Music Education Research 19 (3): 231-251. DOI: 10.1080/14613808.2016.1214695

Higgins, K. (2012). The music between us: Is music a universal language? Chicago: University of Chicago Press.

Jones, E. (Ed.) (2010). Internationalisation and the Student Voice: Higher Education Perspectives. New York: Routledge. 
Kapoor, R. (2007). Auroville: A spiritual-social experiment in human unity and evolution. Futures, 39(5), 632-643.

King, J. T. (2004). Service-learning as a site for critical pedagogy: A case of collaboration, caring, and defamiliarisation across borders. Journal of Experiential Education 26(3), 121-137.

Krishna, T. M. (2013). A Southern Music: The Karnatic Story. Noida: HarperCollins Publishers.

Lewin, R. (Ed.). (2010). The handbook of practice and research in study abroad: Higher education and the quest for global citizenship. Routledge.

Mani, C. (2018). Customised pedagogical tools to aid aural-oral transmission: RagaCurve and gesture. Finnish Journal of Music Education, 21(1), 31-54.

Russell, M. and Vallade, L. (2010). Guided reflective journaling: Assessing the international study and volunteering experience. In Jones, Elspeth (Ed.), Internationalisation and the Student Voice: Higher Education Perspectives, pp. 98-109. New York: Routledge.

Schippers, H. (2009). Facing the music: Shaping music education from a global perspective. Oxford: Oxford University Press.

Turino, T. (2008). Music as social life: The politics of participation. Chicago: University of Chicago Press.

Westerlund, H. M. (2019). The return of moral questions: expanding social epistemology in music education in a time of super-diversity. Music Education Research [Online]. DOI:

$10.1080 / 14613808.2019 .1665006$ 